Review

\title{
Fucoidan as a Marine Anticancer Agent in Preclinical Development
}

\author{
Jong-Young Kwak \\ Department of Biochemistry, School of Medicine and Immune-Network Pioneer Research Center, \\ Dong-A University, 32, Daesingongwon-ro, Seo-gu, Busan 602-714, Korea; \\ E-Mail: jykwak@dau.ac.kr; Tel.: +82-51-240-2856; Fax: +82-51-241-6940
}

Received: 15 November 2013; in revised form: 31 December 2013 / Accepted: 10 January 2014 / Published: 28 January 2014

\begin{abstract}
Fucoidan is a fucose-containing sulfated polysaccharide derived from brown seaweeds, crude extracts of which are commercially available as nutritional supplements. Recent studies have demonstrated antiproliferative, antiangiogenic, and anticancer properties of fucoidan in vitro. Accordingly, the anticancer effects of fucoidan have been shown to vary depending on its structure, while it can target multiple receptors or signaling molecules in various cell types, including tumor cells and immune cells. Low toxicity and the in vitro effects of fucoidan mentioned above make it a suitable agent for cancer prevention or treatment. However, preclinical development of natural marine products requires in vivo examination of purified compounds in animal tumor models. This review discusses the effects of systemic and local administration of fucoidan on tumor growth, angiogenesis, and immune reaction and whether in vivo and in vitro results are likely applicable to the development of fucoidan as a marine anticancer drug.
\end{abstract}

Keywords: fucoidan; anticancer; preclinical; anticancer immunity; antiangiogenesis

\section{Introduction}

Fucoidan is a polysaccharide that consists of sulfated fucose residues. The richest sources of fucoidan are marine organisms, including brown algae species such as Laminaria and Fucus [1]. Fucoidan-rich brown algae have been marketed as a dietary supplement or nutraceutical. Fucoidan has advantages of low toxicity, oral bioavailability, and multiple mechanisms of action. Pharmacologically, fucoidan affects many pathophysiological processes, including inflammation, vascular physiology, carcinogenesis, and oxidative stress [2,3]. Furthermore, fucoidan can easily be extracted using either 
hot water or acidic solutions [4]. Thus, fucoidan-containing food supplements or drinks have been traditionally administered to cancer patients in Korea, Japan, China, and other countries. Although the underlying anticancer effects of fucoidan are largely unknown, it can directly induce cytotoxicity and apoptosis in cancer cells [5]. Fucoidan can also affect cancer cells indirectly e.g., as an antiangiogenic agent. Furthermore, fucoidan has immune-stimulating effects on dendritic cells (DCs) [6-9] and natural killer (NK) cells $[10,11]$. Thus, fucoidan can enhance anticancer immunity through immune cell activation and influx and stimulation of the production of anticancer cytokines.

Fucoidan has been reported to be effective in vivo upon oral, intraperitoneal, or intravenous administration (Table 1). Australian groups have reported clinical trials using fucoidan [12-15]. Recently, Fitton reviewed the potential therapeutic use of fucoidan in various diseases, including infection, chronic inflammation and fibrosis, liver diseases, arthritis, and radiation injury [2]. Biological activities of fucoidan, including anticancer activity, may vary depending on the source of seaweed, compositional and structural traits, charge density, distribution, bonding of the sulfate substitutions, and purity of the fucoidan preparation $[4,16]$.

The structure and function relationships of fucoidan and other sulfated polysaccharides have been reviewed previously $[1,3,16]$. This review discusses the preclinical development and use of fucoidan as a marine anticancer agent, based on in vivo findings in animal models of cancers or other diseases.

\section{Cancer Cell Apoptosis in Vitro}

Although the mechanisms underlying the antitumor activity of fucoidan are diverse, it has antitumor activity by inducing apoptosis in cancer cells. Fucoidan-mediated apoptosis of cancer cells likely involves up-regulation or down-regulation of multiple signaling pathways. However, signaling pathways leading to the apoptosis of cancer cells by fucoidan have not been fully characterized [5]. Recently, in vitro studies have shown the molecular mechanisms of fucoidan in the induction of apoptosis in various human cancer cells, including HL-60, NB4, THP-1, and U937 leukemic cells [17,18], MCF-7 breast cancer cells [19], AGS human gastric adenocarcinoma cells [20], A549 lung carcinoma cells [21], PC-3 prostatic cancer cells [22], and SMMC-7721 hepatocellular carcinoma cells [23]. Xue et al. demonstrated that intraperitoneally injected crude extracts of Fucus vesiculosus induced apoptosis of 4T1 breast cancer cells in tumor-bearing mice, but fucoidan alone did not cause apoptosis of some other cancer cells in vitro [24]. Thinh et al. demonstrated that highly purified fucoidan derived from the brown algae Sargassum mcclurei was less cytotoxic, but inhibited colony formation in DLD-1 colon cancer cells when used at up to $200 \mu \mathrm{g} / \mathrm{mL}$ for $48 \mathrm{~h}$ [25]. We showed previously that fucoidan derived from Fucus vesiculosus failed to induce apoptosis in K562 erythroleukemic [17] and mouse CT26 colon cancer cells [26], while it inhibited cell proliferation. These results suggest that apoptotic activity of fucoidan on cancer cells may be cell type specific. 
Table 1. In vivo effect of fucoidan on tumor growth in tumor-bearing mice.

\begin{tabular}{|c|c|c|c|c|}
\hline Fucoidan & Route/Dose & Tumor Type & Action Mechanism & References \\
\hline Cladosiphon okamuranus & p.o. $5 \mathrm{~g} / \mathrm{kg}$ & 26 colon cancer cells & Natural killer (NK)cell-mediated & {$[11]$} \\
\hline $\begin{array}{c}\text { Fucus vesiculosus } \\
\text { (Sigma, St. Louis, MO, USA) }\end{array}$ & i.p. $5 \mathrm{mg} / \mathrm{kg}$ & $4 \mathrm{~T} 1$ breast cancer cells & $\begin{array}{l}\text { Inhibition of angiogenesis and induction } \\
\text { of apoptosis }\end{array}$ & {$[24,25]$} \\
\hline Fucus evanescence & $10 \mathrm{mg} / \mathrm{kg}$ & Lewis lung carcinoma cells & Unknown & {$[27]$} \\
\hline From Ze Lang Nanjing Med. Tech Co. & i.p. $200 \mathrm{mg} / \mathrm{kg}$ & Bel-7402 hepatocellular carcinoma in nude mice & Inhibition of proliferation & {$[28]$} \\
\hline $\begin{array}{c}\text { Fucus vesiculosus } \\
\text { (Sigma, St. Louis, MO, USA) }\end{array}$ & $\begin{array}{c}\text { Foot-pad injection } \\
0.25 \mathrm{mg} / \text { mice }\end{array}$ & 4T1-xenograft mice & Prevention of metastasis & [29] \\
\hline Sargassum plagiophyllum & p.o. $75 \mathrm{mg} / \mathrm{kg}$ & Diethylnitrosamine-induced hepatocellular carcinoma & Inhibition of carcinogen metabolism & [30] \\
\hline Cladosiphon okamuranus Tokida & p.o. $100 \mathrm{mg} / \mathrm{kg}$ & Sarcoma 180 (S-180)-xenograft & $\begin{array}{l}\text { Delayed tumor growth by nitric oxide } \\
\text { produced by macrophages }\end{array}$ & {$[31]$} \\
\hline Undaria pinnatifida & $\begin{array}{l}\text { Diet containing 1\% Mekabu } \\
\qquad(34 \mathrm{mg} / \text { day })\end{array}$ & A20 leukemia cells & Cytolytic activity by NK cell activation & [32] \\
\hline $\begin{array}{c}\text { Fucus vesiculosus } \\
\text { (Sigma, St. Louis, MO, USA) }\end{array}$ & i.v. $5 \mathrm{mg} / \mathrm{kg}$ & $\begin{array}{l}\text { Lewis lung carcinoma cells } \\
\text { B16 melanoma cells }\end{array}$ & Antiangiogenic effect & {$[33]$} \\
\hline Ascophyllum nodosum & $1 \mathrm{mg} / \mathrm{mice}$ & MOPC-315 plasma cell tumor & Prevention of angiogenesis in tumor tissues & {$[34]$} \\
\hline
\end{tabular}




\section{In Vivo Anticancer Effects}

Tumor-bearing animal models are commonly utilized to study the effects of therapeutic interventions. Recently, fucoidan was shown to inhibit the growth of tumor cells in several animal models (Table 1). Importantly, fucoidan treatment is relatively safe in animals. For example, tumor-bearing mice tolerated repeated injections of a moderate dose of fucoidan $(10 \mathrm{mg} / \mathrm{kg})$ [27]. However, fucoidan at $25 \mathrm{mg} / \mathrm{kg}$ caused toxicity in the same mouse model [27]. When fucoidan derived from Laminaria japonica was administered to rats orally at $300 \mathrm{mg} / \mathrm{kg}$ per day, there were no significant toxic effects [35]. Other groups also demonstrated that there was no difference in body weight between controls and animals treated with $200 \mathrm{mg} / \mathrm{kg}$ of fucoidan administered intraperitoneally [28]. Importantly, in a recent phase-two clinical trial in humans conducted by Myers et al., a seaweed-derived nutrient supplement, containing $75 \mathrm{mg}$ fucoidan plus vitamin B6, zinc, and manganese, was found to be safe when taken orally over four weeks [15]. These results suggest that fucoidan generally has low toxicity and is well tolerated.

A substantial number of animal studies have been conducted for the treatment of cancer using fucoidan. Alekseyenko et al. showed that while a single injection of fucoidan at $25 \mathrm{mg} / \mathrm{kg}$ failed to inhibit tumor growth in mice with transplanted Lewis lung adenocarcinoma, repeated injections of fucoidan at $10 \mathrm{mg} / \mathrm{kg}$ resulted in pronounced antitumor and antimetastatic effects [27]. In a hepatocellular carcinoma xenograft mouse model established by implanting Bel-7402 cells in nu/nu mice, administering fucoidan at $200 \mathrm{mg} / \mathrm{kg}$ intraperitoneally caused an anticancer effect partly by inhibiting the proliferation of cancer cells in vivo, but not by apoptosis [28]. Xue et al. investigated the effects of fucoidan on the metastasis of cancer cells. They demonstrated that crude extracts of fucoidan suppressed lung metastasis of 4T1 breast cancer cells as well as tumor growth [24,36]. Fucoidan markedly reduced the growth rate of $4 \mathrm{~T} 1$ cells and significantly diminished the number of metastatic tumor nodules present in the lungs of 4T1-xenografted mice [29]. Collectively, these results suggest that fucoidan treatment suppresses tumorigenesis and metastasis, supporting the potential development of fucoidan as an anticancer drug.

Molecular mechanisms underlying the mode of action of fucoidan were studied in vivo. Fucoidan was found to prevent diethylnitrosamine-induced hepatocarcinogenesis by inhibiting metabolic activation of the carcinogen [30]. Takeda et al. found that oral administration of fucoidan effectively inhibited growth of implanted Sarcoma-180 cells in xenograft mouse models [31]. Fucoidan likely mediated nitric oxide (NO) release by stimulated macrophages in the tumor microenvironment, thus causing apoptosis. Furthermore, supernatants from fucoidan-stimulated macrophages were found to cause apoptosis of Sarcoma-180 cells. This effect was negated by the addition of a NO synthase inhibitor, $\mathrm{N}^{\mathrm{G}}$-nitro-L-arginine methyl ester (L-NAME) [31]. Xue et al. demonstrated that $\beta$-catenin expression in tumor lesions was decreased significantly by fucoidan treatment of tumor-bearing mice [36]. In addition, fucoidan treatment lowered expression of cyclin D1 and c-myc in vivo. Similar to the in vivo results, in vitro experimental results also demonstrated that fucoidan modulated the $\mathrm{Wnt} / \beta$-catenin signaling pathway. These results suggest that fucoidan exerts anticancer activity at least partly by down-regulating $\beta$-catenin signaling both in vitro and in vivo.

It has been suggested that differing in vivo effects of fucoidans may depend on electrical charge density, extent of sulfonation, and the molecular weight of different preparations [37]. The requirement 
for continuous administration may limit the use of high-molecular-weight (HMW) fucoidan in pharmaceutical and clinical applications [38]. The in vitro anticancer activity of fucoidans derived from the sporophyll of Undaria pinnatifida was significantly higher for low-molecular-weight fucoidan $(490 \mathrm{kDa})$ than for native fucoidan of $5100 \mathrm{kDa}$ [39]. Azuma et al. further investigated molecular-weight dependent effects of fucoidan on tumor growth and survival time in tumor-bearing mouse models [11]. They showed that oral administration of fucoidan extracted from Cladosiphon okamuranus in tumor-bearing mice suppressed colon tumor growth, but the tumor weight was lowered in mice treated with either LMW (6.4-40 kDa) or HMW fucoidan (300-330 kDa) preparations. Therefore, studying the anticancer efficacy of LMW and HMW fucoidan preparations in animal models should be an area of future research efforts.

\section{In Vivo Anticancer Immune Responses}

Maruyama et al. studied mice that were fed a diet containing Mekabu fucoidan, derived from the sporophyll of Undaria pinnatifida [32]. Mice were on the diet for 10 days before subcutaneous inoculation with lymphoma cells. Thereafter, the mice were fed the same diet for 40 days. Cell growth was significantly inhibited in these mice. However, tumor growth was not inhibited in mice fed with fucoidan diet only 40 days after inoculation of lymphoma cells [32]. The authors suggested that this anticancer activity may have been due to activation of an immune response initiated even before inoculation of cancerous cells rather than a direct cytotoxic effect by fucoidan on lymphoma cells. Further in vivo studies have elucidated potential mechanisms underlying the fucoidan-mediated anticancer immune responses. For example, fucoidan can affect immune cell activity and cytokine production. The killer activities of T cell-mediated NK cells were enhanced in mice fed with fucoidan compared to control mice [10,32]. NK cell activation was associated with increased production of interferon (IFN)- $\gamma$ and interleukin (IL)-12 by splenic $\mathrm{T}$ cells in fucoidan-fed mice $[32,40]$. Furthermore, oral administration of fucoidan increased the number of splenic NK cells in tumor-bearing mice [11].

It has been suggested that immunostimulation and immunosuppression occur simultaneously in cancer patients, and deactivation of certain cytokines could offer an unexploited and novel anticancer treatment approach [41]. Cancer-induced immune suppression is related to a defective IL-12-IFN- $\gamma-$ HLA-DR axis [41]. Proinflammatory cytokines such as IL-12 are essential for inducing the Th1 response [42]. In vitro experiments in our laboratory have shown that the secretion of IL-12p70 and IFN- $\gamma$ is enhanced by co-culturing $\mathrm{T}$ cells with fucoidan-activated human peripheral blood DCs, whereas fucoidan-activated DCs alone failed to produce IL-12p70 [8]. On the other hand, $\mathrm{Hu}$ et al. demonstrated that fucoidan could enhance the maturation of DCs and the cross-presentation of cancer testis antigen, NY-ESO- 1 to $\mathrm{CD}^{+} \mathrm{T}$ cells, thus augmenting the cytotoxicity of $\mathrm{T}$ cells against NY-ESO-1-expressing cancer cells [9]. Interestingly, fucoidan was found to increase NY-SEO-1 binding to human DCs [9]. Cancer immunotherapy using DCs generated in vitro has been proven to be safe in clinical trials in combination with a DC activator [43]. Accordingly, we observed that the co-administration of DCs and fucoidan in tumor-bearing mice significantly decreased tumor growth when compared to the administration of DCs or fucoidan alone (in preparation). Therefore, fucoidan could modulate anticancer immune responses against different cancer cell types. 


\section{Antiangiogenic Effects of Fucoidan in Vivo}

Targeting tumor angiogenesis or new vasculature formation has advanced cancer therapy [44]. Limiting new blood vessel formation by antiangiogenic agents reduces intratumoral blood flow, hence limiting growth and metastatic potential. There have been contradictory reports of the effects of fucoidan on angiogenesis. Oversulfated fucoidan was found to inhibit tumor-induced angiogenesis $[33,45]$, whereas fucoidan has been associated with neovascularization in other diseases [46].

Oversulfated fucoidan was found to inhibit the basic fibroblast growth factor (bFGF)-induced tube formation by human umbilical vein endothelial cells [45], while other sulfated polysaccharides inhibited the proliferation and migration of vascular endothelial cells by altering FGF binding to cell surface FGF receptors [47]. In contrast, fucoidan promoted FGF-2 effects in vivo [37] and LMW fucoidan (MW. ca. $4 \mathrm{kDa}$ ) prepared by radical degradation promoted bFGF-induced tube formation of endothelial cells $[48,49]$. On the other hand, in ex vivo angiogenesis assays, where rat aortic tissue was placed on Matrigel $^{\mathrm{TM}}$ and capillary tube formation was measured, fucoidan derived from Undaria pinnatifida suppressed angiogenesis in the aortic rings when used at $100 \mu \mathrm{g} / \mathrm{mL}$ [50]. However, LMW fucoidan reduced intimal hyperplasia in a rat aortic allograft model of transplant atherosclerosis, while stimulating formation of an endothelial lining in the vascular allograft [51]. Wang and Miao reviewed the currently used marine-derived angiogenesis inhibitors, suggesting that different fucoidan preparations affect angiogenesis differently, depending on molecular weight and extent of sulfation: (1) LMW fucoidans (4-9 kDa) stimulated angiogenesis in different assays; (2) mid-molecular-weight fucoidans (15-20 kDa) enhanced HUVEC migration, but have not been shown to inhibit HUVEC tube formation; and (3) natural fucoidans of HMW (30 kDa) showed antiangiogenic properties by inhibiting proliferation, migration, and tube formation of endothelial cells and inhibiting vascular network formation [52].

Koyanagi et al. demonstrated that fucoidan prevented phosphorylation of the receptor for vascular endothelial growth factor (VEGF) upon VEGF binding [33]. Furthermore, the authors observed that repetitive intravenous administration of fucoidan at $5 \mathrm{mg} / \mathrm{kg}$ in mice suppressed neovascularization from surrounding blood vessels in the region adjacent to implanted Sarcoma 180 cells. Similarly, intraperitoneal administration of fucoidan ( $1 \mathrm{mg} / \mathrm{mouse})$ in mice implanted with the murine plasma cell tumor line, MOPC-315, which expresses VEGF, reduced VEGF-induced angiogenesis, tumor neovascularization, and tumor growth [34]. In 2012, Xue et al. demonstrated that fucoidan caused a significant reduction in intratumoral VEGF expression in mice implanted with 4T1 breast cancer cells compared to untreated control animals [24]. These promising results indicate that fucoidan could play an important role as an antiangiogenic factor in cancer. Further investigations of angiogenesis using various in vivo cancer models treated with fucoidan are warranted.

\section{Mobilization of Hematopoietic Progenitor Cells}

Reportedly, fucoidan can inhibit selectin function in vitro and in vivo [53]. Fucoidan blocks leukocyte rolling and interferes with various inflammatory responses in animal models [54-58]. In addition, it can reduce platelet aggregation by inhibiting P-selectin [59]. However, significant mobilization of progenitor cells and leukocytosis could be elicited in selectin-deficient mice similar 
to that of wild-type controls, suggesting that the mode of action of fucoidan is not through selectins [60,61]. The in vivo effects of fucoidan on leukocytes in other disease models are summarized in Table 2.

Table 2. In vivo effects of fucoidan on leukocytes in various disease models.

\begin{tabular}{|c|c|c|c|c|}
\hline Test & Route & Dose & Possible in vivo effects & References \\
\hline Human & p.o. & $330 \mathrm{mg}$ & Mobilization of leukocytes & [12] \\
\hline Human & p.o. & $100 \mathrm{mg}$ & Immune modulation & {$[15]$} \\
\hline Rabbit & i.v. & $10 \mathrm{mg} / \mathrm{kg}$ & $\begin{array}{l}\text { Decreased influx of leukocytes into cerebrospinal } \\
\text { fluid in meningitis }\end{array}$ & {$[58]$} \\
\hline Mice & $\begin{array}{l}\text { i.v. } \\
\text { i.p. }\end{array}$ & $\begin{array}{l}50 \mathrm{mg} / \mathrm{kg} \\
50 \mathrm{mg} / \mathrm{kg}\end{array}$ & $\begin{array}{l}\text { Mobilization of hematopoietic progenitor stem cells } \\
\text { (HPCs) }\end{array}$ & [61-63] \\
\hline Rat & i.p. & $25 \mathrm{mg} / \mathrm{kg}$ & $\begin{array}{l}\text { Inhibition of extravasation of macrophages and } \mathrm{CD} 4^{+} \\
\mathrm{T} \text { cells to myocardium }\end{array}$ & {$[64]$} \\
\hline Mice & p.o. & $200 \mathrm{mg} / \mathrm{kg}$ & Th1 switch in Leishmania infection & {$[65]$} \\
\hline Mice & i.p. & $50 \mathrm{mg} / \mathrm{kg}$ & Improvement of pulmonary inflammation & {$[66]$} \\
\hline Rat & i.p. & $50 \mathrm{mg} / \mathrm{kg}$ & Inhibition of leukocyte infiltration in ischemic lesion & {$[67]$} \\
\hline Mice & i.v. & $10 \mathrm{mg} / \mathrm{kg}$ & Inhibition of infiltration of $\gamma \delta \mathrm{T}$ cells in pleural cavity & {$[68]$} \\
\hline Mice & p.o. & $\begin{array}{l}0.05 \%(\mathrm{w} / \mathrm{w}) \\
\text { in mouse chow }\end{array}$ & Improvement of chronic colitis & [69] \\
\hline Mice & i.v. & $25 \mathrm{mg} / \mathrm{kg}$ & Inhibition of leukocyte rolling & {$[70]$} \\
\hline Rat & p.o. & $100 \mathrm{mg} / \mathrm{kg}$ & $\begin{array}{l}\text { Decreased infiltration of neutrophils in myocardial } \\
\text { infarct size }\end{array}$ & [71] \\
\hline Cat & i.v. & $25 \mathrm{mg} / \mathrm{kg}$ & Inhibition of leukocyte rolling & {$[72]$} \\
\hline
\end{tabular}

Interaction between stromal-derived factor-1 (SDF-1, CXCL12) and SDF-1 $\alpha$-binding chemokine (C-X-C motif) receptor 4 (CXCR4) is involved in the mobilization of hematopoietic progenitor stem cells (HPC), which are used after high-dose chemotherapy to support bone marrow regeneration [73]. In addition, CXCR4 is expressed on various cancer cell types [41,74], and the CXCL12-CXCR4 axis is involved in tumor progression, angiogenesis, metastasis, and survival [74-76]. Therefore, modulation of the CXCL12-CXCR4 axis by fucoidan seems an interesting target for cancer therapy. Fucoidan binds CXCL12, which is normally retained by heparan sulfate proteoglycans on the membrane of stromal cells or the extracellular matrix in bone marrow, thereby releasing CXCL12 into the circulation [60,77-79]. Negatively charged fucoidan seems to interact with basic residues of CXCL12 [80]. When mice were injected intravenously or intraperitoneally with 50 or $100 \mathrm{mg} / \mathrm{kg}$ of fucoidan, HPCs were mobilized from bone marrow [60-62], and plasma concentration of CXCL12 increased rapidly and dramatically $[37,61,63]$. In clinical trials, Irhimeh et al. demonstrated that oral fucoidan increased surface expression of CXCR4 on human $\mathrm{CD}_{3} 4^{+}$cells and the release of CD34 cells from bone marrow to peripheral blood [12]. Therefore, future studies are warranted to determine whether fucoidan can affect the CXCL12-CXCR4 axis in tumor growth in vivo.

\section{Role of Scavenger Receptor Type A in the Action of Fucoidan}

Fucoidan is known to bind to various types of scavenger receptors (SR), including class A-, B-, and F-SRs [81-83]. Fucoidan has been used as an effective competitor for oxidized low-density 
lipoproteins in SR-A binding assays [84]. SR-A is mainly expressed in macrophages and DCs [85] and is implicated in changing the immune microenvironment in cancer. However, the reports on the role of SR-A in anticancer immunity have been contradictory. Wang et al. demonstrated that anticancer responses in SR-A ${ }^{-/}$mice were improved and correlated with an increased antigen-specific $\mathrm{T}$ cell response [86]. The authors showed that $\mathrm{SR}-\mathrm{A}^{-/-}$mice were highly responsive to inflammatory stimuli, such as lipopolysaccharide. Thus, the immunosuppressive role of SR-A in cancer might be due to its inhibition of proinflammatory responses by ligation of the toll-like receptor 4 (TLR4) rather than a direct inhibition of tumor immunity [87]. Indeed, it was shown that fucoidan, as a common SR-A ligand, also activated TLR4 signaling, and combined signaling through two distinct receptors resulting in a functional outcome not achieved by either receptor alone [88].

SR-A expression was lower in cancerous than in normal tissues and SR-A depletion was found to boost growth and angiogenesis of implanted Lewis lung carcinoma in mice [89]. Tumor cells caused SR-A up-regulation on macrophages [90], and elimination of SR-A-positive tumor-infiltrating leukocytes from the peritoneum of tumor-bearing mice relieved the $\mathrm{T}$ cell suppression and inhibited tumor growth $[91,92]$. Moreover, SR-A ${ }^{-/}$mice showed delayed growth of injected EL4 tumors and expression of inducible NO synthase, while showing significantly increased IFN- $\gamma$ mRNA expression, suggesting that tumor-associated macrophages are highly active in SR-A-depleted conditions [93]. Recently, in vitro experimental results revealed that fucoidan can inhibit macrophage-induced tumor cell invasion [94]. Results obtained using an experimental autoimmune myocarditis model also showed that fucoidan administration attenuated progression of myocarditis by decreasing myocardial macrophage infiltration [64]. Therefore, we can speculate that macrophages are associated with immune suppression in tumor tissues and macrophage depletion in cancerous tissues by fucoidan may inhibit tumor progression.

In vitro testing indicated that LMW fucoidan is internalized via endocytosis [38]. Recently, Zhu et al. demonstrated that fucoidan-SR-A internalization occurred through clathrin- and caveolae-dependent pathways [95]. They also revealed the mechanism involving the production of tumor necrosis factor (TNF)- $\alpha$ following SR-A binding by fucoidan. Fucoidan treatment of macrophages could promote recruitment of the major vault protein to lipid rafts to form an SR-A-major vault protein complex, leading to TNF- $\alpha$ production [96]. NO production by macrophages was significantly decreased in SR-A ${ }^{-/}$compared with the wild-type mice when macrophages were treated with fucoidan [97]. In addition, fucoidan abrogated SR-A-mediated chaperone uptake into macrophages [98] and DCs [83]. Our previous results also demonstrated that fucoidan decreased the binding of the anti-SR-A antibody to human blood DCs and failed to activate SR-A-depleted DCs [8]. These results suggest that the binding of SR-A by fucoidan leads to DC activation. Herber et al. demonstrated that DCs with high lipid content had low antigen-processing capacity and the frequencies of these cells were significantly increased in tumor-bearing mice and cancer patients [99]. Accumulation of lipids by DCs in vitro and in vivo was induced by tumor-derived factors that up-regulated SR-A expression on DCs. It was shown that SR-A overexpressing DCs could internalize modified lipoproteins from serum and fucoidan inhibited DC lipid uptake. Therefore, fucoidan might be effective in decreasing the frequency of lipid-laden and poorly antigen-presenting DCs in cancer patients by blocking SR-A, thus leading to an enhanced immune response. Consequently, further 
studies to reveal the possible effects of fucoidan on tumor growth in SR-A $\mathrm{A}^{-/}$mice may help to unravel the immunological roles of fucoidan in cancer.

\section{In Vivo Cytokine Production by Fucoidan in Other Diseases}

In contrast to effects on cytokine expression in tumor-bearing mice, serum analysis of cytokines after fucoidan treatment has shown discrepant effects in several other disease models (Table 3). For example, splenic cytokine analysis in Leishmania-infected mice showed that fucoidan treatment at $200 \mathrm{mg} / \mathrm{kg}$ (p.o.) significantly increased levels of IFN- $\gamma$, IL-12, and TNF- $\alpha$ [65]. In an aspirin-induced stomach ulceration model, IFN- $\gamma$ was increased, and levels of IFN- $\gamma$ were further increased in rats treated with both aspirin and fucoidan at $400 \mathrm{mg} / \mathrm{kg}$ [100]. On the other hand, Maruyama et al. demonstrated that Mekabu-derived fucoidan suppressed production of Th2 cytokines in the bronchoalveolar lavage fluid after ovalbumin aerosol challenge [66]. Under normal conditions, intravenous treatment of mice and nonhuman primates with fucoidan was shown to increase levels of IL-8, monocyte chemoattractant protein 1 , and matrix metalloproteinase $9[60,63]$.

Other studies have shown that fucoidan suppresses cytokine levels in several disease models. Kang et al. demonstrated that treatment of rats with fucoidan at $50 \mathrm{mg} / \mathrm{kg}$ (i.p.) significantly decreased the number of the TNF- $\alpha$-immunoreactive cells in the cerebral cortex and striatum, induced by lipopolysaccharide [67]. Concanavalin A-induced liver injury and a concomitant increase of plasma TNF- $\alpha$ and IFN- $\gamma$ levels were prevented, but plasma IL-10 levels were increased by fucoidan treatment at $30 \mathrm{mg} / \mathrm{kg}$ (i.v.) [101]. Interestingly, the above mentioned inhibitory effects of fucoidan were reversed by pretreatment with an anti-mouse IL-10 antibody. Intravenous administration of fucoidan inhibited ovalbumin-induced $\gamma \delta \mathrm{T}$ cell accumulation in pleural cavities and lymph nodes in a murine model of ovalbumin-induced allergic pleurisy [68]. Moreover, pleural $\gamma \delta \mathrm{T}$ lymphocytes from fucoidan-treated mice showed reduced ovalbumin-induced IL-5 production, leading to decreased ovalbumin-induced eosinophil influx [68]. These results indicate that cytokine production profiles of fucoidan-stimulated immune cells in cancer patients may differ from those in patients with inflammatory or immune diseases.

\section{In Vivo Antioxidant and Prooxidant Effects of Fucoidan}

Prooxidant cytotoxic effects are important in clearing transformed cells from the body and limiting tumor growth. In contrast, oxidative stress is also associated with membrane lipid peroxidation, DNA damage, and mutagenesis, leading to tumor formation [102]. Fucoidan may have both antioxidant and prooxidant effects in cancer cells. We previously showed that fucoidan-induced apoptosis in leukemic cells was inhibited by glutathione and/or NAME addition [17]. Furthermore, fucoidan treatment of leukemic cells decreased intracellular glutathione concentrations and stimulated NO production. Zhang et al. demonstrated that fucoidan enhanced the apoptosis of cancer cells that responded to cisplatin, tamoxifen, or paclitaxel treatment via reduced glutathione levels, and enhanced production of intracellular reactive oxygen species in breast cancer cells [103]. According to Yang et al., fucoidan isolated from Undaria pinnatifida induces the death of hepatocellular carcinoma cells by causing intracellular accumulation of high levels of reactive oxygen species, accompanied by damage to the mitochondrial ultrastructure, depolarization of the mitochondrial membrane potential, and caspase 
activation [23]. These results suggest that induction of oxidative stress may be an important event in fucoidan-induced cancer cell death.

Table 3. Changes of cytokine and growth factor levels by in vivo administration of fucoidan in cancer and other disease models.

\begin{tabular}{|c|c|c|}
\hline Cytokines & In Vivo Changes & References \\
\hline \multirow{2}{*}{ CXCL12 } & Increase in plasma & {$[37,51,61,63,80]$} \\
\hline & Increase in myocardial ischemic tissue & [46] \\
\hline \multirow{4}{*}{ IFN- $\gamma$} & Increase in splenic T cells/A20 lymphoma & {$[32]$} \\
\hline & Increase in splenic $\mathrm{T}$ cells/P-388 & {$[40]$} \\
\hline & Increase of secretion in plasma by aspirin & [100] \\
\hline & Inhibition of increase in gastric ulcer lesion & [104] \\
\hline \multirow{5}{*}{ TNF- $\alpha$} & Inhibition of increase in acute bacterial meningitis & {$[58]$} \\
\hline & Inhibition of expression in ischemic lesion & {$[67]$} \\
\hline & Inhibition of increase in ischemia-reperfusion injury & {$[71]$} \\
\hline & Inhibition of increase in gastric ulcer lesion & [104] \\
\hline & Inhibition of lipopolysaccharide-induced increase in brain & [105] \\
\hline IL-1 & Inhibition of increase in acute bacterial meningitis & {$[58]$} \\
\hline \multirow{2}{*}{ IL-4 } & Decrease in bronchoalveolar lavage fluid & {$[66]$} \\
\hline & Decrease in ovalbumin-sensitized spleen cells & [106] \\
\hline IL-5 & Inhibition of increase in pleural cavity of allergic pleurisy & {$[68]$} \\
\hline \multirow{3}{*}{ IL-6 } & Decrease in plasma & {$[15]$} \\
\hline & Inhibition of increase in colonic lamina propria of colitis & [69] \\
\hline & Inhibition of increase in ischemia-reperfusion injury & [71] \\
\hline \multirow{2}{*}{ IL-8 } & Increase in plasma & [63] \\
\hline & Inhibition of lipopolysaccharide-induced increase in brain & {$[67,105]$} \\
\hline \multirow{2}{*}{ IL-10 } & Increase in plasma level in liver injury & {$[101]$} \\
\hline & Inhibition of decrease in ischemia-reperfusion injury & [71] \\
\hline \multirow{3}{*}{ IL-12 } & Increase in splenic T cells/A20 lymphoma & {$[32]$} \\
\hline & Increase in Leishmania infection & {$[65]$} \\
\hline & Inhibition of increase in gastric ulcer lesion & [104] \\
\hline MCP-1 & Increase in plasma & {$[63]$} \\
\hline \multirow{2}{*}{ VEGF } & Reduction of mRNA expression in tumor tissues & {$[24]$} \\
\hline & Increase in myocardial ischemic tissue & [46] \\
\hline FGF-2 & Potentiation of activity & [37] \\
\hline
\end{tabular}

In general, fucoidan preparations show antioxidant effects in other disease models in vivo [107-109] (summarized in Table 4). Pre-treating rats with fucoidan preparations caused suppression of lactate dehydrogenase and malondialdehyde levels, but caused normalization of superoxide dismutase, catalase, and glutathione peroxidase levels, decreasing necrosis and cirrhosis incidences in the liver of $\mathrm{CCL}_{4}$-treated rats [107]. Similarly, fibrosis and acetaminophen-induced liver injury were significantly suppressed by oral fucoidan intake [110,111]. Luo et al. investigated the effects of fucoidan on 1-methyl-4-phenyl-1,2,3,6-tetrahydropyridine (MPTP)-induced animal models of parkinsonism in C57/BL mice. The authors demonstrated that the administration of fucoidan at $25 \mathrm{mg} / \mathrm{kg}$ (i.p.) inhibited MPTP-induced lipid peroxidation and reduced the activities of antioxidant enzymes [108]. 
This fucoidan-induced alteration in antioxidant activity might lead to increased levels of striatal dopamine and its metabolite, increased expression of tyrosine hydroxylase, and reduced behavioral deficits. Suresh et al. demonstrated that fucoidan prevented increase of drug-metabolizing hepatic enzyme levels, which result from oxidative stress by diethylnitrosamine, a carcinogen in rats [30]. In contrast, splenocytes of fucoidan-treated mice infected with Leishmania donovani generated significantly high levels of superoxide and NO [65].

Table 4. In vivo effects of fucoidan on other diseases related to the oxidant production.

\begin{tabular}{ccclc}
\hline Test & Route & Dose & \multicolumn{1}{c}{ Possible in vivo effects } & References \\
\hline Mice & i.p. & $\begin{array}{c}25 \mathrm{mg} / \mathrm{kg} \\
15 \mathrm{mg} / \mathrm{kg}\end{array}$ & $\begin{array}{l}\text { Prevention of MPTP-induced neurotoxicity } \\
\text { Prevention of lipopolysaccharide-induced } \\
\text { neurotoxicity }\end{array}$ & {$[108]$} \\
\hline Mice & i.p. & $25 \mathrm{mg} / \mathrm{kg}$ & Neuroprotection via antioxidant activity & {$[105]$} \\
\hline Mice & i.p. & $100 \mathrm{mg} / \mathrm{kg}$ & Prevention of ischemia-reperfusion injury & {$[108]$} \\
\hline \multirow{2}{*}{ Rat } & p.o. & $100 \mathrm{mg} / \mathrm{kg}$ & $\begin{array}{l}\text { Suppression of liver fibrogenesis and drug-induced } \\
\text { liver injury }\end{array}$ & {$[110,111]$} \\
\hline
\end{tabular}

Similar to fucoidan, green tea has shown both antioxidant and prooxidant effects in cancer cells [113]. Prooxidant effects of green tea apparently cause tumor cell apoptosis and also induce endogenous antioxidant mechanisms that protect against carcinogenic insults in normal tissues [113]. Fucoidan has antioxidative and prooxidative potential in animal models of renal ischemia-reperfusion injury, however, fucoidan alone did not affect malondialdehyde and superoxide dismutase levels in the sham-operated group [112]. Recently, it was shown that intracellular and secreted $\mathrm{H}_{2} \mathrm{O}_{2}$ from $\mathrm{HT} 1080$ human fibrosarcoma cells were both greatly repressed upon tumor cell treatment with enzyme-digested fucoidan preparations extracted from seaweed Mozuku of Cladosiphon novae-caledoniae kylin [114]. However, Ye et al. suggested that $\mathrm{H}_{2} \mathrm{O}_{2}$ release by cancer cells is one of the triggering factors to promote angiogenesis rather than apoptosis [114]. Therefore, more careful in vivo studies using highly purified fucoidan preparations are essential to determine whether fucoidan has an antioxidant or prooxidant role in cancer prevention and treatment.

\section{Conclusions}

Fucoidan shows promising characteristics that warrant further development of the substance as a future marine drug. Recent in vivo studies suggest fucoidan to be a potential preventive or therapeutic agent for controlling cancers. However, the in vitro and in vivo mechanisms underlying the observed anticancer effects of fucoidan have not been fully investigated. The anticancer effects of fucoidan in vivo may be due to the inhibition of tumorigenesis and metastasis. More importantly, fucoidan may act by promoting immune responses or antiangiogenesis in tumor tissues. The mobilization of hematopoietic progenitor cells by fucoidan is yet another interesting characteristic of the substance that harbors therapeutic potential. These findings need to be corroborated by further preclinical studies. Orally delivered fucoidan appears promising as a marine drug in several diseases [2], but fucoidan administration via other routes is also possible. However, fucoidan preparations isolated from different sources have shown differential anticancer effects in vivo because of correspondingly different structural 
properties. Therefore, as a next step, the determination of the structural characteristics responsible for the in vivo anticancer activities of fucoidan will be essential for its potential use as a marine drug.

\section{Acknowledgments}

This work was supported by the Pioneer Research Center Program through the National Research Foundation of Korea funded by the Ministry of Science, ICT \& Future Planning (2012-0009583 and 2012-0009664).

\section{Conflicts of Interest}

The authors declare no conflict of interest.

\section{References}

1. Pomin, V.H.; Mourão, P.A. Structure, biology, evolution, and medical importance of sulfated fucans and galactans. Glycobiology 2008, 18, 1016-1027.

2. Fitton, J.H. Therapies from fucoidan; multifunctional marine polymers. Mar. Drugs 2011, 9, 1731-1760.

3. Pomin, V.H. Fucanomics and galactanomics: Current status in drug discovery, mechanisms of action and role of the well-defined structures. Biochim. Biophys. Acta 2012, 1820, 1971-1979.

4. Berteau, O.; Mulloy, B. Sulfated fucans, fresh perspectives: Structures, functions, and biological properties of sulfated fucans and an overview of enzymes active towards this class of polysaccharide. Glycobiology 2003, 13, 29-40.

5. Senthilkumar, K.; Manivasagan, P.; Venkatesan, J.; Kim, S.K. Brown seaweed fucoidan: Biological activity and apoptosis, growth signaling mechanism in cancer. Int. J. Biol. Macromol. 2013, 60, 366-374.

6. Kim, M.H.; Joo, H.G. Immunostimulatory effects of fucoidan on bone marrow-derived dendritic cells. Immunol. Lett. 2008, 115, 138-143.

7. Yang, M.; Ma, C.; Sun, J.; Shao, Q.; Gao, W.; Zhang, Y.; Li, Z.; Xie, Q.; Dong, Z.; Qu, X. Fucoidan stimulation induces a functional maturation of human monocyte-derived dendritic cells. Int. Immunopharmacol. 2008, 8, 1754-1760.

8. Jin, J.O.; Park, H.Y.; Xu, Q.; Park, J.I.; Zvyagintseva, T.; Stonik, V.A.; Kwak, J.Y. Ligand of scavenger receptor class A indirectly induces maturation of human blood dendritic cells via production of tumor necrosis factor- $\alpha$. Blood 2009, 113, 5839-5847.

9. Hu, Y.; Cheng, S.C.; Chan, K.T.; Ke, Y.; Xue, B.; Sin, F.W.; Zeng, C.; Xie, Y. Fucoidin enhances dendritic cell-mediated T-cell cytotoxicity against NY-ESO-1 expressing human cancer cells. Biochem. Biophys. Res. Commun. 2010, 392, 329-334.

10. Ale, M.T.; Maruyama, H.; Tamauchi, H.; Mikkelsen, J.D.; Meyer, A.S. Fucoidan from Sargassum sp. and Fucus vesiculosus reduces cell viability of lung carcinoma and melanoma cells in vitro and activates natural killer cells in mice in vivo. Int. J. Biol. Macromol. 2011, 49, 331-336. 
11. Azuma, K.; Ishihara, T.; Nakamoto, H.; Amaha, T.; Osaki, T.; Tsuka, T.; Imagawa, T.; Minami, S.; Takashima, O.; Ifuku, S.; Morimoto, M.; et al. Effects of oral administration of fucoidan extracted from Cladosiphon okamuranus on tumor growth and survival time in a tumor-bearing mouse model. Mar. Drugs 2012, 10, 2337-2348.

12. Irhimeh, M.R.; Fitton, J.H.; Lowenthal, R.M. Fucoidan ingestion increases the expression of CXCR4 on human CD34+ cells. Exp. Hematol. 2007, 35, 989-994.

13. Irhimeh, M.R.; Fitton, J.H.; Lowenthal, R.M. Pilot clinical study to evaluate the anticoagulant activity of fucoidan. Blood Coagul. Fibrinolysis 2009, 20, 607-610.

14. Myers, S.P.; O’Connor, J.; Fitton, J.H.; Brooks, L.; Rolfe, M.; Connellan, P.; Wohlmuth, H.; Cheras, P.A.; Morris, C. A combined phase I and II open label study on the effects of a seaweed extract nutrient complex on osteoarthritis. Biologics 2010, 4, 33-44.

15. Myers, S.P.; O’Connor, J.; Fitton, J.H.; Brooks, L.; Rolfe, M.; Connellan, P.; Wohlmuth, H.; Cheras, P.A.; Morris, C. A combined Phase I and II open-label study on the immunomodulatory effects of seaweed extract nutrient complex. Biologics 2011, 5, 45-60.

16. Kusaykin, M.; Bakunina, I.; Sova, V.; Ermakova, S.; Kuznetsova, T.; Besednova, N.; Zaporozhets, T.; Zvyagintseva, T. Structure, biological activity, and enzymatic transformation of fucoidans from the brown seaweeds. Biotechnol. J. 2008, 3, 904-915.

17. Jin, J.O.; Song, M.G.; Kim, Y.N.; Park, J.I.; Kwak, J.Y. The mechanism of fucoidan-induced apoptosis in leukemic cells: Involvement of ERK1/2, JNK, glutathione, and nitric oxide. Mol. Carcinog. 2010, 49, 771-782.

18. Park, H.S.; Hwang, H.J.; Kim, G.Y.; Cha, H.J.; Kim, W.J.; Kim, N.D.; Yoo, Y.H.; Choi, Y.H. Induction of apoptosis by fucoidan in human leukemia U937 cells through activation of p38 MAPK and modulation of Bcl-2 family. Mar. Drugs 2013, 11, 2347-2364.

19. Zhang, Z.; Teruya, K.; Eto, H.; Shirahata, S. Fucoidan extract induces apoptosis in MCF-7 cells via a mechanism involving the ROS-dependent JNK activation and mitochondria-mediated pathways. PLoS One 2011, 6, e27441.

20. Park, H.S.; Kim, G.Y.; Nam, T.J.; Kim, N.D.; Choi, Y.H. Antiproliferative activity of fucoidan was associated with the induction of apoptosis and autophagy in AGS human gastric cancer cells. J. Food Sci. 2011, 76, T77-T83.

21. Boo, H.J.; Hyun, J.H.; Kim, S.C.; Kang, J.I.; Kim, M.K.; Kim, S.Y.; Cho, H.; Yoo, E.S.; Kang, H.K. Fucoidan from Undaria pinnatifida induces apoptosis in A549 human lung carcinoma cells. Phytother. Res. 2011, 25, 1082-1086.

22. Boo, H.J.; Hong, J.Y.; Kim, S.C.; Kang, J.I.; Kim, M.K.; Kim, E.J.; Hyun, J.W.; Koh, Y.S.; Yoo, E.S.; Kwon, J.M.; et al. The anticancer effect of fucoidan in PC-3 prostate cancer cells. Mar. Drugs 2013, 11, 2982-2999.

23. Yang, L.; Wang, P.; Wang, H.; Li, Q.; Teng, H.; Liu, Z.; Yang, W.; Hou, L.; Zou, X. Fucoidan derived from Undaria pinnatifida induces apoptosis in human hepatocellular carcinoma SMMC-7721 cells via the ROS-mediated mitochondrial pathway. Mar. Drugs 2013, 11, 1961-1976.

24. Xue, M.; Ge, Y.; Zhang, J.; Wang, Q.; Hou, L.; Liu, Y.; Sun, L.; Li, Q. Anticancer properties and mechanisms of fucoidan on mouse breast cancer in vitro and in vivo. PLoS One 2012, 7, e43483. 
25. Thinh, P.D.; Menshova, R.V.; Ermakova, S.P.; Anastyuk, S.D.; Ly, B.M.; Zvyagintseva, T.N. Structural characteristics and anticancer activity of fucoidan from the brown alga Sargassum mcclurei. Mar. Drugs 2013, 11, 1456-1476.

26. Kim, C.H.; Kim, C.G.; Kwak, J.Y. Role of scavenger receptor type A in the migration of dendritic cells and immunogenic antitumor effects by fucoidan. Dong-A University, Busan, Korea. 2014, unpublished work.

27. Alekseyenko, T.V.; Zhanayeva, S.Y.; Venediktova, A.A.; Zvyagintseva, T.N.; Kuznetsova, T.A.; Besednova, N.N.; Korolenko, T.A. Antitumor and antimetastatic activity of fucoidan, a sulfated polysaccharide isolated from the Okhotsk Sea Fucus evanescens brown alga. Bull. Exp. Biol. Med. 2007, 143, 730-732.

28. Zhu, C.; Cao, R.; Zhang, S.X.; Man, Y.N.; Wu, X.Z. Fucoidan inhibits the growth of hepatocellular carcinoma independent of angiogenesis. Evid. Based Complement. Alternat. Med. 2013, 2013, doi:10.1155/2013/692549.

29. Hsu, H.Y.; Lin, T.Y.; Hwang, P.A.; Tseng, L.M.; Chen, R.H.; Tsao, S.M.; Hsu, J. Fucoidan induces changes in the epithelial to mesenchymal transition and decreases metastasis by enhancing ubiquitin-dependent TGF $\beta$ receptor degradation in breast cancer. Carcinogenesis 2013, 34, 874-884.

30. Suresh, V.; Anbazhagan, C.; Thangam, R.; Senthilkumar, D.; Senthilkumar, N.; Kannan, S.; Rengasamy, R.; Palani, P. Stabilization of mitochondrial and microsomal function of fucoidan from Sargassum plagiophyllum in diethylnitrosamine induced hepatocarcinogenesis. Carbohydr. Polym. 2013, 92, 1377-1385.

31. Takeda, K.; Tomimori, K.; Kimura, R.; Ishikawa, C.; Nowling, T.K.; Mori, N. Anti-tumor activity of fucoidan is mediated by nitric oxide released from macrophages. Int. J. Oncol. 2012, 40, 251-260.

32. Maruyama, H.; Tamauchi, H.; Iizuka, M.; Nakano, T. The role of NK cells in antitumor activity of dietary fucoidan from Undaria pinnatifida sporophylls (Mekabu). Planta Med. 2006, 72, 1415-1417.

33. Koyanagi, S.; Tanigawa, N.; Nakagawa, H.; Soeda, S.; Shimeno, H. Oversulfation of fucoidan enhances its anti-angiogenic and antitumor activities. Biochem. Pharmacol. 2003, 65, 173-179.

34. Narazaki, M.; Segarra, M.; Tosato, G. Sulfated polysaccharides identified as inducers of neuropilin-1 internalization and functional inhibition of VEGF165 and semaphorin3A. Blood 2008, 111, 4126-4136.

35. Li, N.; Zhang, Q.; Song, J. Toxicological evaluation of fucoidan extracted from Laminaria japonica in Wistar rats. Food Chem. Toxicol. 2005, 43, 421-426.

36. Xue, M.; Ge, Y.; Zhang, J.; Liu, Y.; Wang, Q.; Hou, L.; Zheng, Z. Fucoidan inhibited 4T1 mouse breast cancer cell growth in vivo and in vitro via downregulation of Wnt/ $\beta$-catenin signaling. Nutr. Cancer 2013, 65, 460-468.

37. Luyt, C.E.; Meddahi-Pellé, A.; Ho-Tin-Noe, B.; Colliec-Jouault, S.; Guezennec, J.; Louedec, L.; Prats, H.; Jacob, M.P.; Osborne-Pellegrin, M.; Letourneur, D.; et al. Low-molecular-weight fucoidan promotes therapeutic revascularization in a rat model of critical hindlimb ischemia. J. Pharmacol. Exp. Ther. 2003, 305, 24-30. 
38. Deux, J.F.; Meddahi-Pellé, A.; le Blanche, A.F.; Feldman, L.J.; Colliec-Jouault, S.; Brée, F.; Boudghène, F.; Michel, J.B.; Letourneur, D. Low molecular weight fucoidan prevents neointimal hyperplasia in rabbit iliac artery in-stent restenosis model. Arterioscler. Thromb. Vasc. Biol. 2002, 22, 1604-1609.

39. Yang, C.; Chung, D.; Shin, I.S.; Lee, H.; Kim, J.; Lee, Y.; You, S. Effects of molecular weight and hydrolysis conditions on anticancer activity of fucoidans from sporophyll of Undaria pinnatifida. Int. J. Biol. Macromol. 2008, 43, 433-437.

40. Maruyama, H.; Tamauchi, H.; Hashimoto, M.; Nakano, T. Antitumor activity and immune response of Mekabu fucoidan extracted from Sporophyll of Undaria pinnatifida. In Vivo 2003, $17,245-249$.

41. Lippitz, B.E. Cytokine patterns in patients with cancer: A systematic review. Lancet Oncol. 2013, 14, e218-e228.

42. Menges, M.; Rössner, S.; Voigtländer, C.; Schindler, H.; Kukutsch, N.A.; Bogdan, C.; Erb, K.; Schuler, G.; Lutz, M.B. Repetitive injections of dendritic cells matured with tumor necrosis factor $\alpha$ induce antigen-specific protection of mice from autoimmunity. J. Exp. Med. 2002, 195, $15-21$.

43. Palucka, K.; Banchereau, J. Cancer immunotherapy via dendritic cells. Nat. Rev. Cancer 2012, 12, 265-277.

44. Tejpar, S.; Prenen, H.; Mazzone, M. Overcoming resistance to antiangiogenic therapies. Oncologist 2012, 17, 1039-1050.

45. Soeda, S.; Kozako, T.; Iwata, K.; Shimeno, H. Oversulfated fucoidan inhibits the basic fibroblast growth factor-induced tube formation by human umbilical vein endothelial cells: Its possible mechanism of action. Biochim. Biophys. Acta 2000, 1497, 127-134.

46. Manzo-Silberman, S.; Louedec, L.; Meilhac, O.; Letourneur, D.; Michel, J.B.; Elmadbouh, I. Therapeutic potential of fucoidan in myocardial ischemia. J. Cardiovasc. Pharmacol. 2011, 58, 626-632.

47. Foxall, C.; Wei, Z.; Schaefer, M.E.; Casabonne, M.; Fugedi, P.; Peto, C.; Castellot, J.J., Jr.; Brandley, B.K. Sulfated malto-oligosaccharides bind to basic FGF, inhibit endothelial cell proliferation, and disrupt endothelial cell tube formation. J. Cell. Physiol. 1996, 168, 657-667.

48. Chabut, D.; Fischer, A.-M.; Colliec-Jouault, S.; Laurendeau, I.; Matou, S.; Le Bonniec, B.; Helley, D. Low molecular weight fucoidan and heparin enhance the basic fibroblast growth factor-induced tube formation of endothelial cells through heparin sulfate-dependent $\alpha 6$ overexpression. Mol. Pharmcol. 2003, 64, 696-702.

49. Chabut, D.; Fischer, A.M.; Helley, D.; Colliec, S. Low molecular weight fucoidan promotes FGF-2-induced vascular tube formation by human endothelial cells, with decreased PAI-1 release and ICAM-1 downregulation. Thrombosis Res. 2004, 113, 93-95.

50. Liu, F.; Wang, J.; Chang, A.K.; Liu, B.; Yang, L.; Li, Q.; Wang, P.; Zou, X. Fucoidan extract derived from Undaria pinnatifida inhibits angiogenesis by human umbilical vein endothelial cells. Phytomedicine 2012, 19, 797-803.

51. Fréguin-Bouilland, C.; Alkhatib, B.; David, N.; Lallemand, F.; Henry, J.P.; Godin, M.; Thuillez, C.; Plissonnier, D. Low molecular weight fucoidan prevents neointimal hyperplasia after aortic allografting. Transplantation 2007, 83, 1234-1241. 
52. Wang, Y.Q.; Miao, Z.H. Marine-derived angiogenesis inhibitors for cancer therapy. Mar. Drugs 2013, 11, 903-933.

53. Arfors, K.E.; Ley, K. Sulfated polysaccharides in inflammation. J. Lab. Clin. Med. 1993, 121, 201-202.

54. Lindbom, L.; Xie, X.; Raud, J.; Hedqvist, P. Chemoattractant-induced firm adhesion of leukocytes to vascular endothelium in vivo is critically dependent on initial leukocyte rolling. Acta Physiol. Scand. 1992, 146, 415-421.

55. Ley, K.; Linnemann, G.; Meinen, M.; Stoolman, L.M.; Gaehtgens, P. Fucoidin, but not yeast polyphosphomannan PPME, inhibits leukocyte rolling in venules of the rat mesentery. Blood 1993, 81, 177-185.

56. Shimaoka, M.; Ikeda, M.; Iida, T.; Taenaka, N.; Yoshiya, I.; Honda, T. Fucoidin, a potent inhibitor of leukocyte rolling, prevents neutrophil influx into phorbol-ester-induced inflammatory sites in rabbit lungs. Am. J. Respir. Crit. Care Med. 1996, 153, 307-311.

57. Hickey, M.J.; Reinhardt, P.H.; Ostrovsky, L.; Jones, W.M.; Jutila, M.A.; Payne, D.; Elliott, J.; Kubes, P. Tumor necrosis factor- $\alpha$ induces leukocyte recruitment by different mechanisms in vivo and in vitro. J. Immunol. 1997, 158, 3391-3400.

58. Granert, C.; Raud, J.; Waage, A.; Lindquist, L. Effects of polysaccharide fucoidin on cerebrospinal fluid interleukin-1 and tumor necrosis factor a in pneumococcal meningitis in the rabbit. Infect. Immun. 1999, 67, 2071-2074.

59. Bachelet, L.; Bertholon, I.; Lavigne, D.; Vassy, R.; Jandrot-Perrus, M.; Chaubet, F.; Letourneur, D. Affinity of low molecular weight fucoidan for P-selectin triggers its binding to activated human platelets. Biochim. Biophys. Acta 2009, 1790, 141-146.

60. Sweeney, E.A.; Priestley, G.V.; Nakamoto, B.; Collins, R.G.; Beaudet, A.L.; Papayannopoulou, T. Mobilization of stem/progenitor cells by sulfated polysaccharides does not require selectin presence. Proc. Natl. Acad. Sci. USA 2000, 97, 6544-6549.

61. Hidalgo, A.; Peired, A.J.; Weiss, L.A.; Katayama, Y.; Frenette, P.S. The integrin $\alpha \mathrm{M} \beta 2$ anchors hematopoietic progenitors in the bone marrow during enforced mobilization. Blood 2004, 104, 993-1001.

62. Frenette, P.S.; Weiss, L. Sulfated glycans induce rapid hematopoietic progenitor cell mobilization: Evidence for selectin-dependent and independent mechanisms. Blood 2000, 96, 2460-2468.

63. Sweeney, E.A.; Lortat-Jacob, H.; Priestley, G.V.; Nakamoto, B.; Papayannopoulou, T. Sulfated polysaccharides increase plasma levels of SDF-1 in monkeys and mice: Involvement in mobilization of stem/progenitor cells. Blood 2002, 99, 44-51.

64. Tanaka, K.; Ito, M.; Kodama, M.; Tomita, M.; Kimura, S.; Hoyano, M.; Mitsuma, W.; Hirono, S.; Hanawa, H.; Aizawa, Y. Sulfated polysaccharide fucoidan ameliorates experimental autoimmune myocarditis in rats. J. Cardiovasc. Pharmacol. Ther. 2011, 16, 79-86.

65. Kar, S.; Sharma, G.; Das, P.K. Fucoidan cures infection with both antimony-susceptible and -resistant strains of Leishmania donovani through Th1 response and macrophage-derived oxidants. Antimicrob. Chemother. 2011, 66, 618-625. 
66. Maruyama, H.; Tamauchi, H.; Hashimoto, M.; Nakano, T. Suppression of Th2 immune responses by mekabu fucoidan from Undaria pinnatifida sporophylls. Int. Arch. Allergy Immunol. 2005, 137, 289-294.

67. Kang, G.H.; Yan, B.C.; Cho, G.S.; Kim, W.K.; Lee, C.H.; Cho, J.H.; Kim, M.; Kang, I.J.; Won, M.H.; Lee, J.C. Neuroprotective effect of fucoidin on lipopolysaccharide accelerated cerebral ischemic injury through inhibition of cytokine expression and neutrophil infiltration. J. Neurol. Sci. 2012, 318, 25-30.

68. Costa, M.F.; Nihei, J.; Mengel, J.; Henriques, M.G.; Penido, C. Requirement of L-selectin for $\gamma \delta \mathrm{T}$ lymphocyte activation and migration during allergic pleurisy: Co-relation with eosinophil accumulation. Int. Immunopharmacol. 2009, 9, 303-312.

69. Matsumoto, S.; Nagaoka, M.; Hara, T.; Kimura-Takagi, I.; Mistuyama, K.; Ueyama, S. Fucoidan derived from Cladosiphon okamuranus Tokida ameliorates murine chronic colitis through the down-regulation of interleukin-6 production on colonic epithelial cells. Clin. Exp. Immunol. 2004, 136, 432-439.

70. Zhang, X.W.; Liu, Q.; Thorlacius, H. Inhibition of selectin function and leukocyte rolling protects against dextran sodium sulfate-induced murine colitis. Scand. J. Gastroenterol. 2001, $36,270-275$.

71. Li, C.; Gao, Y.; Xing, Y.; Zhu, H.; Shen, J.; Tian, J. Fucoidan, a sulfated polysaccharide from brown algae, against myocardial ischemia-reperfusion injury in rats via regulating the inflammation response. Food Chem. Toxicol. 2011, 49, 2090-2095.

72. Granert, C.; Raud, J.; Xie, X.; Lindquist, L.; Lindbom, L. Inhibition of leukocyte rolling with polysaccharide fucoidin prevents pleocytosis in experimental meningitis in the rabbit. J. Clin. Investig. 1994, 93, 929-936.

73. Nervi, B.; Link, D.C.; DiPersio, J.F. Cytokines and hematopoietic stem cell mobilization. J. Cell. Biochem. 2006, 99, 690-705.

74. Zlotnik, A. New insights on the role of CXCR4 in cancer metastasis. J. Pathol. 2008, 215, 211-213.

75. Furusato, B.; Mohamed, A.; Uhlén, M.; Rhim, J.S. CXCR4 and cancer. Pathol. Int. 2010, 60, 497-505.

76. Teicher, B.A.; Fricker, S.P. CXCL12 (SDF-1)/CXCR4 pathway in cancer. Clin. Cancer Res. 2010, 16, 2927-2931.

77. Amara, A.; Lorthioir, O.; Valenzuela, A.; Magerus, A.; Thelen, M.; Montes, M.; Virelizier, J.L.; Delepierre, M.; Baleux, F.; Lortat-Jacob, H.; et al. Stromal cell-derived factor-1 $\alpha$ associates with heparan sulfates through the first $\beta$-strand of the chemokine. J. Biol. Chem. 1999, 274, 23916-23925.

78. Sadir, R.; Baleux, F.; Grosdidier, A.; Imberty, A.; Lortat-Jacob, H. Characterization of the stromal cell-derived factor-1 $\alpha$-heparin complex. J. Biol. Chem. 2001, 276, 8288-8296.

79. Lortat-Jacob, H.; Grosdidier, A.; Imberty, A. Structural diversity of heparan sulfate binding domains in chemokines. Proc. Natl. Acad. Sci. USA 2002, 99, 1229-1234.

80. Sweeney, E.A.; Papayannopoulou, T. Increase in circulating SDF-1 after treatment with sulphated glycans, the role of SDF-1 in mobilization. Ann. N. Y. Acad. Sci. 2001, 938, 48-52.

81. Peiser, L.S.; Gordon, S. The function of scavenger receptors expressed by macrophages and their role in the regulation of inflammation. Microbes Infect. 2001, 3, 149-159. 
82. Tamura, Y.; Adachi, H.; Osuga, J.; Ohashi, K.; Yahagi, N.; Sekiya, M.; Okazaki, H.; Tomita, S.; Iizuka, Y.; Shimano, H.; et al. FEEL-1 and FEEL-2 are endocytic receptors for advanced glycation end products. J. Biol. Chem. 2003, 278, 12613-12617.

83. Berwin, B.; Delneste, Y.; Lovingood, R.V.; Post, S.R.; Pizzo, S.V. SREC-I, a type F scavenger receptor, is an endocytic receptor for calreticulin. J. Biol. Chem. 2004, 279, 51250-51257.

84. Brown, M.S.; Goldstein, J.L. Lipoprotein metabolism in the macrophage: Implications for cholesterol deposition in atherosclerosis. Annu. Rev. Biochem. 1983, 52, 223-261.

85. Platt, N.; Gordon, S. Is the class A macrophage scavenger receptor (SR-A) multifunctional?-The mouse's tale. J. Clin. Investig. 2001, 108, 649-654.

86. Wang, X.Y.; Facciponte, J.; Chen, X.; Subjeck, J.R.; Repasky, E.A. Scavenger receptor-A negatively regulates antitumor immunity. Cancer Res. 2007, 67, 4996-5002.

87. Becker, M.; Cotena, A.; Gordon, S.; Platt, N. Expression of the class A macrophage scavenger receptor on specific subpopulations of murine dendritic cells limits their endotoxin response. Eur. J. Immunol. 2006, 36, 950-960.

88. Seimon, T.A.; Obstfeld, A.; Moore, K.J.; Golenbock, D.T.; Tabas, I. Combinatorial pattern recognition receptor signaling alters the balance of life and death in macrophages. Proc. Natl. Acad. Sci. USA 2006, 103, 19794-19799.

89. Ben, J.; Jin, G.; Zhang, Y.; Ma, B.; Bai, H.; Chen, J.; Zhang, H.; Gong, Q.; Zhou, X.; Zhang, H.; et al. Class A scavenger receptor deficiency exacerbates lung tumorigenesis by cultivating a procarcinogenic microenvironment in humans and mice. Am. J. Respir. Crit. Care Med. 2012, $186,763-772$.

90. Hagemann, T.; Wilson, J.; Burke, F.; Kulbe, H.; Li, N.F.; Plüddemann, A.; Charles, K.; Gordon, S.; Balkwill, F.R. Ovarian cancer cells polarize macrophages toward a tumor-associated phenotype. J. Immunol. 2006, 176, 5023-5032.

91. Bak, S.P.; Walters, J.J.; Takeya, M.; Conejo-Garcia, J.R.; Berwin, B.L. Scavenger receptor-A-targeted leukocyte depletion inhibits peritoneal ovarian tumor progression. Cancer Res. 2007, 67, 4783-4789.

92. Peter, S.; Bak, G.; Hart, K.; Berwin, B. Ovarian tumor-induced T cell suppression is alleviated by vascular leukocyte depletion. Transl. Oncol. 2009, 2, 291-299.

93. Komohara, Y.; Takemura, K.; Lei, X.F.; Sakashita, N.; Harada, M.; Suzuki, H.; Kodama, T.; Takeya, M. Delayed growth of EL4 lymphoma in SR-A-deficient mice is due to upregulation of nitric oxide and interferon- $\gamma$ production by tumor-associated macrophages. Cancer Sci. 2009, 100, 2160-2166.

94. Neyen, C.; Plüddemann, A.; Mukhopadhyay, S.; Maniati, E.; Bossard, M.; Gordon, S.; Hagemann, T. Macrophage scavenger receptor a promotes tumor progression in murine models of ovarian and pancreatic cancer. J. Immunol. 2013, 190, 3798-3805.

95. Zhu, X.D.; Zhuang, Y.; Ben, J.J.; Qian, L.L.; Huang, H.P.; Bai, H.; Sha, J.H.; He, Z.G.; Chen, Q. Caveolae-Dependent endocytosis is required for class A macrophage scavenger receptor-mediated apoptosis in macrophages. J. Biol. Chem. 2011, 286, 8231-8239.

96. Ben, J.; Zhang, Y.; Zhou, R.; Zhang, H.; Zhu, X.; Li, X.; Zhang, H.; Li, N.; Zhou, X.; Bai, H.; et al. Major vault protein regulates class A scavenger receptor-mediated tumor necrosis factor- $\alpha$ synthesis and apoptosis in macrophages. J. Biol. Chem. 2013, 288, 20076-20084. 
97. Nakamura, T.; Suzuki, H.; Wada, Y.; Kodama, T.; Doi, T. Fucoidan induces nitric oxide production via p38 mitogen-activated protein kinase and NF- $\mathrm{BB}-d e p e n d e n t$ signaling pathways through macrophage scavenger receptors. Biochem. Biophys. Res. Commun. 2006, 343, 286-294.

98. Berwin, B.; Hart, J.P.; Rice, S.; Gass, C.; Pizzo, S.V.; Post, S.R.; Nicchitta, C.V. Scavenger receptor-A mediates gp96/GRP94 and calreticulin internalization by antigen-presenting cells. EMBO J. 2003, 22, 6127-6136.

99. Herber, D.L.; Cao, W.; Nefedova, Y.; Novitskiy, S.V.; Nagaraj, S.; Tyurin, V.A.; Corzo, A.; Cho, H.I.; Celis, E.; Lennox, B.; et al. Lipid accumulation and dendritic cell dysfunction in cancer. Nat. Med. 2010, 16, 880-886.

100. Choi, J.I.; Raghavendran, H.R.; Sung, N.Y.; Kim, J.H.; Chun, B.S.; Ahn, D.H.; Choi, H.S.; Kang, K.W.; Lee, J.W. Effect of fucoidan on aspirin-induced stomach ulceration in rats. Chem. Biol. Interact. 2010, 183, 249-254.

101. Saito, A.; Yoneda, M.; Yokohama, S.; Okada, M.; Haneda, M.; Nakamura, K. Fucoidan prevents concanavalin A-induced liver injury through induction of endogenous IL-10 in mice. Hepatol. Res. 2006, 35, 190-198.

102. Cleveland, J.L.; Kastan, M.B. Cancer. A radical approach to treatment. Nature 2000, 407, 309-311.

103. Zhang, Z.; Teruya, K.; Yoshida, T.; Eto, H.; Shirahata, S. Fucoidan extract enhances the anti-cancer activity of chemotherapeutic agents in MDA-MB-231 and MCF-7 breast cancer cells. Mar. Drugs 2013, 11, 81-98.

104. Raghavendran, H.R.; Srinivasan, P.; Rekha, S. Immunomodulatory activity of fucoidan against aspirin-induced gastric mucosal damage in rats. Int. Immunopharmacol. 2011, 11, 157-163.

105. Cui, Y.Q.; Jia, Y.J.; Zhang, T.; Zhang, Q.B.; Wang, X.M. Fucoidan protects against lipopolysaccharide-induced rat neuronal damage and inhibits the production of proinflammatory mediators in primary microglia. CNS Neurosci. Ther. 2012, 18, 827-833.

106. Yanase, Y.; Hiragun, T.; Uchida, K.; Ishii, K.; Oomizu, S.; Suzuki, H.; Mihara, S.; Iwamoto, K.; Matsuo, H.; Onishi, N.; et al. Peritoneal injection of fucoidan suppresses the increase of plasma IgE induced by OVA-sensitization. Biochem. Biophys. Res. Commun. 2009, 387, 435-439.

107. Kang, K.S.; Kim, I.D.; Kwon, R.H.; Lee, J.Y.; Kang, J.S.; Ha, B.J. The effects of fucoidan extracts on $\mathrm{CCl}_{4}$-induced liver injury. Arch. Pharm. Res. 2008, 31, 622-627.

108. Luo, D.; Zhang, Q.; Wang, H.; Cui, Y.; Sun, Z.; Yang, J.; Zheng, Y.; Jia, J.; Yu, F.; Wang, X.; et al. Fucoidan protects against dopaminergic neuron death in vivo and in vitro. Eur. J. Pharmacol. 2009, 617, 33-40.

109. Balboa, E.M.; Conde, E.; Moure, A.; Falqué, E.; Domínguez, H. In vitro antioxidant properties of crude extracts and compounds from brown algae. Food Chem. 2013, 138, 1764-1785.

110. Hong, S.W.; Jung, K.H.; Lee, H.S.; Zheng, H.M; Choi, M.J.; Lee, C.; Hong, S.S. Suppression by fucoidan of liver fibrogenesis via the TGF- $\beta /$ Smad pathway in protecting against oxidative stress. Biosci. Biotechnol. Biochem. 2011, 75, 833-840.

111. Hong, S.W.; Lee, H.S.; Jung, K.H.; Lee, H.; Hong, S.S. Protective effect of fucoidan against acetaminophen-induced liver injury. Arch. Pharm. Res. 2012, 35, 1099-1105. 
112. Chen, J.; Wang, W.; Zhang, Q.; Li, F.; Lei, T.; Luo, D.; Zhou, H.; Yang, B. Low molecular weight fucoidan against renal ischemia-reperfusion injury via inhibition of the MAPK signaling pathway. PLoS One 2013, 8, e56224.

113. Lambert, J.D.; Elias, R.J. The antioxidant and pro-oxidant activities of green tea polyphenols: A role in cancer prevention. Arch. Biochem. Biophys. 2010, 501, 65-72.

114. Ye, J.; Li, Y.; Teruya, K.; Katakura, Y.; Ichikawa, A.; Eto, H.; Hosoi, M.; Hosoi, M.; Nishimoto, S.; Shirahata, S. Enzyme-Digested fucoidan extracts derived from seaweed Mozuku of Cladosiphon novae-caledoniae kylin inhibit invasion and angiogenesis of tumor cells. Cytotechnology 2005, 47, 117-126.

(C) 2014 by the authors; licensee MDPI, Basel, Switzerland. This article is an open access article distributed under the terms and conditions of the Creative Commons Attribution license (http://creativecommons.org/licenses/by/3.0/). 